\title{
The Effects of Fire Products on Escape Capability in Primates and Human Fire Victims
}

\author{
DAVID A. PURSER \\ Huntingdon Research Centre Ltd. \\ Huntingdon, Cambridgeshire, England
}

\begin{abstract}
Animal studies of incapacitation by thermal decomposition products indicate that the common asphyxiant gases, $\mathrm{CO}$, $\mathrm{HON}$, low $\mathrm{O}_{2}$ and $\mathrm{CO}_{2}$ are almost certainly responsible for the severe narcosis and death of fire victims overcome by smoke. Eye and upper respiratory tract irritation also probably i air escape capability but to an unknown degree. Time to narcottc incapacitation in man should be predictable if the fire profile in terms of the above gases is known. Incapacitation of victims of smouldering and post-flashover fires can be explained in these terms, but victims should be able to escape from early flaming fires. It is suggested that the high incidence of victims in the room of fire origin may be partly due to sleeping victims being intoxicated by co during the smouldering phase.
\end{abstract}

\section{INTRODUCTION}

Statistical surveys of fire casualties in the uK during the mid $1970^{\prime}$ 's revealed that not only were a large proportion of fatal and non-fatal fire casualties being reported in the category "overcome by smoke and toxic gases" rather than by heat and burns, but that there was a four-fold increase in this category between 1955 and 1971 (1). This increasing trend has continued over the last decade so that now approximately half of all fatal casualties and a third of all non-fatal casualties of fires in dwellings, the majority caused by fires in furniture and bedding, are reported as being overcome by smoke and toxic gases (2). This has occurred desplte the fact that the total annul numbers of fires have remained approximately constant over this period of time.

There is therefore good evidence that smoke and toxic gases are a considerable problem in fires and in general two rather different approaches have been used to evaluate the toxicity associated with buming materials. Once consists basically of a 'black box' approach, whereby materials are decomosed in a standard small scale apparatus and materials are ranked on the basis of rodent LC50s (3). The problems with this approach are that little attempt is usually made to identify the decomposition products responsible for the toxicity and that laboratory scale furnaces cannot recreate the comlex temperature/time/product profiles occurring in large scale fires. The other approach is to measure the conditions in large scale fire tests in terms of temperature, smoke density and the profiles of the major toxic products with time (usually without animal exposures) and then to attempt to predict the likely effects on human fire victims from a knowledge of the toxicity of specific fire gases. This approach suffers from an inadequate knowledge of the important toxic fire products and exactly how they cause incapacitation and death individually and in combination(4).

However, if it could be demonstrated that toxic effects in fires are caused by a small number of identifiable products, then by studying the effects of these gases individually and in combination it should be possible, by measurements of the concentration/time profiles of the common fire gases, to predict how a person confronted with a particular situation would be incapacitated and how their ability to escape would be 
affected. The main function of small scale toxiclty tests would then be to confirm. that the toxicity associated with particular burning materials was due to the common toxic fire products, by means of chemical atmosphere analysis and animal exposures, and to identify those cases where unusual toxic effects occurred(5).

At Euntingdon Research Centre we have been studying the effects of combustion atmospheres on animals, mainly primates, at sublethal levels to examine the mechanisms whereby people become incapacitated in fires ${ }^{(6)}$.

\section{INCAPACITATION BY COMBUSTION PRODUCTS}

As a result of the animal exposures to combustion product atmospheres from a wide range of materials it was found that despite the great complexity in chemical composition of the products the basic toxic effects on the animals were relatively simple, and for each individual smoke atmosphere the toxiclty was always dominated by a narcotic gas or by irritants $(6)$. Interactions between individual narcotic gases, or between narcotics and irritants, were found to be minor, so that a reasonably good predictive model of incapacitation could be developed by considering each of a small number of individual toxic gases as acting separately. From the results of these animal.studies and available human data a model has been developed for predicting the incapacitating effects of fire products on victims and the time during exposure when they should occur, to determine likely effects on escape capability. This is achieved by consideration of 2 sources of information:

1. An extrapolation Erom animal data and such human data as is available to determine probable time to and nature of incapacitation for common fire products;

2. Consideration of the concentration/time profiles of the fire products in large scale experimental fires of different types.

These predictions have then been compared with data on real fire victims, derived from the Strathclyde fire victim pathology studies (7). Home office statistics(2) and a small number of case reports, in an attempt to test the predictability of the model and to determine if this approach helps to explain how people are affected physiologically by fire and how some mitigation of toxic hazard in fires might be achieved.

\section{NARCOSIS BY FIRE GASES}

Narcotic gases cause incapacitation mainly by effects upon the central nervous system, and to some extent the cardiovascular system(8). In general time to incapacitation and its severity are predictable in that there is usually a relatively sharp cut of between a near nomal state and one of severe incapacitation $(6,9)$. Most narcotic fire gases produce their effects by causing brain tissue hypoxia(8,10), and since the body posesses powerful adaptive mechanisms designed to maximize oxygen delivery to the brain it is usualiy possible to maintain normal body function up to a certain concentration or dose of narcotic. However once the point is reached where normal function can no longer be maintained deterioration is rapid and severe, beginning with signs similar to the effects of alcohol, consisting of lethargy or euphoria with poor physical coordination followed rapidiy by unconsciousness and death if exposure continues $(9,10)$. The major narcotic gases found in fires are $\mathrm{Co}, \mathrm{HCN}, \mathrm{low} \mathrm{O}_{2}$ and high $\mathrm{CO}_{2}(6,11)$.

$\mathrm{CO}$

The most important narcotic fire gas is co which presents a serious hazard at concentrations of approximately 100 ppm and above. In the strathclyde pathology study (7) lethal levels ( $>50 \%$ carboxyhaemoglobin) were found in 548 of all fatalities, while some 698 of victims had carboxyheamoglobin levels capable of causing incapacitation (>308 carboxyhaemoglobin). Incapacitating levels of carboxyhaenoglobin were also common in victims surviving the immediate fire, so that $c o$ is evidently important as a cause of both incapacitation and death. Co uptake and intoxication are extremely insidious. During the early stages, as the carboxyhaemoglobin levels build up gradually in the blood, the effects are minimal, and in low level exposures in man(12) the first symptoms were of a heacache at 15-20\% carboxyhaemoglobin, and objective tests at these levels show on $1 y$ minor performance deficits. When significant effects do occur their onset is sudden and rapid(9), and the degree of incapacitation is severe, so that by the time a victim is aware that he is affected he is probably unable to take effective action. These findings may explain why deaths from co derived from defective heating appliances 
are so common. Survivors of such situations often report that they, or other victims that died, experienced headaches or nausea, but had no ldea of the cause, so they did not attempt to leave the area until overcome by fumes (13).

During the early stages of incapacitation the main effects appear to be on motivation and psychomotor ability, with a tendency for the victim to sleep if left undisturbed(9). Under these conditions one might expect a subject, if alerted by a sudden: noise such as of breaking glass (often reported by fire survivors) to 'sober up' and rouse himself sufficiently to make an escape attempt. Bowever such a victim is likely to fat for 3 reasons:

Firstly because this stage is rapidiy followed by unconsciousness and coma;

secondly because active subjects are seriously affected at carboxyhaemoglobin concentrations which have only minor effects on sedentary subjects. Thus whereas sedentary animals were often unaffected at carboxyhaemoglobin levels of up to $40 \%$, those

engaged in light activity were seriousiy affected at carboxyhaemoglobin levels in the 25-35\% range(9). Similarly, in one human study, although a sedentary subject could perform tasks such as writing, even at the exceptionally high level of 558 carboxyhaemoglobir, the subject collapsed and became unconscious immediately when he attempted to get up and walk(14). Thus if a victim in a bec or chair did attempt to escape not only would he be in danger of a rapid collapse due to continued co uptake, but even if no further uptake occurred, the ability to perform even light work or exercise would be severely impatred, and even the simple act of rising from a horizontal to an upright position could precipate loss of consclousness;

The third important feature is that the rate of uptake of $C$ depends on the respiration (respiratory minute volume - RMV) and hence the activity of the subject.

A MODEL FOR THE PREDICTION OF TIME TO INCAPACITATION BY CO IN FIRES

FIGURE I

TIME TO INCAPACITATION BY CARBON MONOXIDE FOR A $70 \mathrm{~kg}$ MAN AT DIFFERENT LEVELS OF ACTIVITY

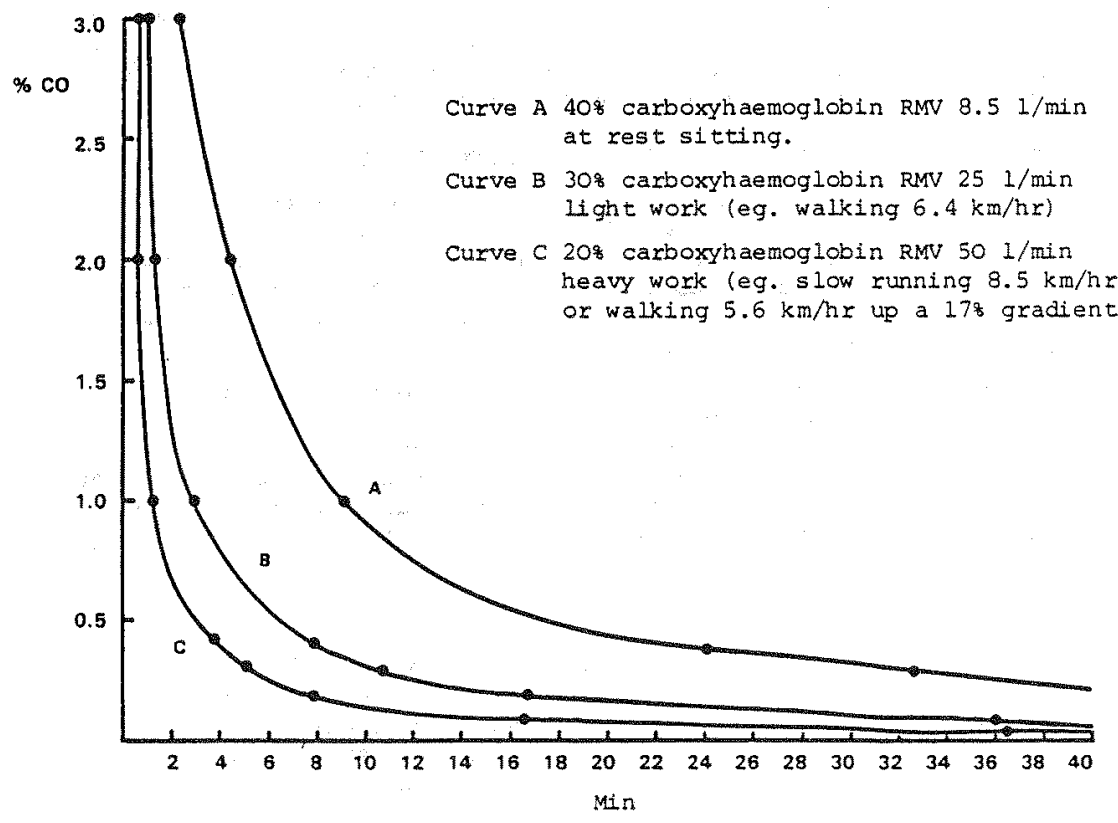


Incapacitation by co depends upon a cose accumulated over a period of the until a carboxyheamoglobin concentration is reached where compensatory mechantsms fail and collapse occurs. In order to predfct time to incapacitation of fire victims due to co it is necessary to know the carboxyhaemoglobin concentrations at which incapacitation is likely to occur and the rate of uptake of $C O$ so that the time to achieve this concentration can be calculated. The caxboxyhaemoglobin concentrations likely to cause incapacitation depend upon the activity of the victim and should be similar to those measured in the primate experfments (9). The rate of $c 0$ uptake in man can be calculated using the Coburn Foster Kane equation(15). From these data I have constructed Figure 1 , which shows the probable time to incapacitation (loss of consciousness) for a $70 \mathrm{~kg}$ man exposed to different co concentrations at 3 levels of activity. The figure shows that the degree of activity can have a major effect on time to incapacteation.

HON

Cyanide has been measured in the blood of both fatal(16) and non-fatal(17) fire victims. However in the strathclyde fire fatality study high concentrations of cyanide in the blood of victims were usually assoctated with lethal levels of carboxyhaemoglobin, so that the role of cyanide as a cause of incapacitation was difficult to determine (16). It is also dificult to relate blood cyanide levels from samples collected after a fire to likely HCN exposure, since the dynamics. of HCN uptake and removal from the blood are poorly unders tood (18).

The pattem of incapacitation for $\mathrm{BCN}$ is somewhat different from that produced by $\infty$ in that the ffects occur more rapldy, as unlike $C O$, HCN is not held almost exclusively in the blood, but carried rapldiy to the brain (19). With Hon although the accumulation of a dose is one factor, the most important determinant of incapacitation appears to be the rate of uptake of $\mathrm{BCN}$, which in tum depends upon the-HCN concentration in the smoke and the subjects' respiration. Thus in the animal experiments $(8,18)$, it was found that at HCN concentrations below approximately $80 \mathrm{ppm}$ the effects were minor over periods of up to 1 hour, with a mila background. hyperventilation. At concentrations above $80 \mathrm{ppm}$ up to approximately $180 \mathrm{ppm}$ an episode of hyperventilation with subsequent unconsciousness occurred at some time during a 30 minuţe period and there was a loose linear relationship between Har concentration and time to incapacitation while above $180 \mathrm{ppm}$ the hyperventilatory episode began immediately with unconsciousness occurring within a few minutes. Data on human exposures to HCN is limited but Kimmerle(20) does quote some approximate data showing a similar effect in man, with incapacitation occurring after 20-30 minutes at $100 \mathrm{ppm}$ HON and after 2 minutes at 200 ppm, death occurring rapialy at concentrations of above approximately $300 \mathrm{ppm}$.

\section{A MODEL FOR THE PREDICTION OF TIME TO INCAPACITATION BY HCN IN FIRES}

From these results it is possible to predict that HCN concentrations below a threshold concentration of approximately $80 \mathrm{ppm}$ will have only minor effect over perlods of up to 1 hour. From $80-180 \mathrm{ppm}$ the time to incapacitation (unconsciousness) will be between 2 and 30 minutes according approximately to the relationship: Time to incapacitation $=(\mathrm{ppm} \mathrm{HCN}-185) /-4.4$. For concentrattons above approximately $180 \mathrm{ppm}$ incapacitation will occur very rapidly (0-2 minutes).

HoN could be particularly dangerous in fires due to its rapid knock down effect, and low HCN levels in the 100-200 ppm range could cause fire victims to loose consciousness rapidly and remain in the fire to die later as a result of accumulation of $\infty$ or some other factor. Also a small change in HCN concentration could cause a large decrease in time to incapacitation so that for example doubling the concentration from 100 to $200 \mathrm{ppm}$ could bring the incapacitation time down from approximately 20 minutes to approximately 2 minutes $(18,20)$.

\section{HYPOXIA}

Apart from the tissue hypoxia caused by $\mathrm{CO}$ and $\mathrm{HCr}$, hypoxia in fires can also be caused by low oxygen exposure. Due to physiological compensatory mechanisms hypoxia has little effect down to $15 \% \mathrm{O}_{2}$, but as the level decreases towards $10 \% \mathrm{O}_{2}$ these compensatory mechanisms begin to fail and narcotic intoxication with lethargy, and sometimes euphoria rapidly occurs. This is followed by unconsciousness, and death at concentrations below $780_{2}(8,10,20)$. 
Carbon dioxide, like carbon monoxide, is unlversally present in fires. It is not toxic at concentrations up to $5 \%$. However at $5 \%$ breathing is strongly stimulated (by a factor of 3) (8), and this hyperventilation, apart from being stressful, can increase the rate at which other toxic fire products (such as $C O$ ) are taken up. However at concentrations above $5 \% \mathrm{CO}_{2}$ is itself narcotic, at 7-10\% unconsciousness unconsciousness occurs in man after a few minutes $(21,22,23)$.

\section{PREDICTION OF TIME TO INCAPACITAIION BY LOW $\mathrm{O}_{2}$ or $\mathrm{CO}_{2}$}

For these two gases the degree of incapacitation does not appear to increase significantly with time once squilibrium has been established, over periods of up to 30 minutes $(8,1.0)$, but narcosis is likely to occur over perlods of upto 5 minutes below a threshold concentration of approximately $128 \mathrm{O}_{2}$ or above approximately $108 \mathrm{CO}_{2}$. Also at either of these concentrations. it is likely that exercise tolerance will be severely reduced (10).

\section{INTERACTIONS BEIWEEN TOXIC FIRE GASES}

The effects of interactions between comblnations of these gases on time to incapacitation in fires is an area that requires further investigation as little information is available. The most important effect is that hyperventilation due to $\mathrm{CO}_{2}$ exposure is likely to increase the rate of uptake of other toxic gases and thus decrease time to incapacitation in proportion to the increase in breathing. For other combinations Co/ Low $\mathrm{O}_{2} / \mathrm{HCN}$, available data suggest that only minor interactive effects are likely (24), so that if allowance is made for hyperventilation due to $\mathrm{CO}_{2}$, errors in estimation of time to incapacitation will probably not be great $(<20 \%)$ if narcotic gases are assumed to act independently at concentrations existing in practical fire situations.

\section{IRRITANT FIRE PRODUCTS}

Unlike the incapacitating effects of narcotics, which are clear cut and well understood, the incapacitative effects of irritants are much more difficult to determine. Irritant fire products produce incapacitation by their painful effects upon the eyes and upper respiratory tract, and to some extent also the lungs. They can also be dangerous to victims surviving the immediate fire exposure, producing a pulmonary irritant response consisting of oedema and inflammation which can cause respiratory difficulties and even death 6-24 hours after exposure $(25,26)$. The effects do not show the sharp cut off of narcosis, but lie on a continuum from mild eye irritation to severe pain, depending upon the concentration of the ixritant andits potency $(27,28,29)$. The effects do not depend upon an accumulated dose but occur immediately upon exposure, and usually lessen somewhat if exposure continues $(6,29)$.

The effects of low concentrations of irritants can best be considered as adding to the obscurational effects of smoke by producing mild eye and upper respiratory tract irritation. In this situation irat tants may have some effect by impairing the speed of movement through a building, as would visual obscuration. The limitation of escape capability may not be simply limited to direct physiological effects, but also to physchological and behavioural effects such as the willingness of an individual to enter a smoke filled corridor $(30)$.

At the other end of the scale when irritants are present at high concentrations there is some disagreement about the likely degree of incapacitation. Some investigators believe that the painful effects on the eyes and upper respiratory tract would be severely incapacitating, so that for example escape from a building would be rendered extremely difficult(3i). Others believe that the effects peak out at moderate concentrations, and that although the effects way be very unpleasant they would not significantly impaix the ability to escape from a building and that they would provide a strong stimulus to escape that might almost be beneficial(32).

The most extensive studies of the effects of severe irritancy in man have been performed on volunteers exposed to riot control agents such as CS (o-chlorobenzy lidine malonitrole) or $\mathrm{CN}$ (a-chloroacetophenone). Even these studies do not really show how the ability to escape from a building might be effected but they do to some extent convey the severity of the effects. The effects of CS, which are probably similar 
to those of any severe sensory irritant, have been described by Beswick et al(29). They consist of an almost instantaneous severe inflamation of the eyes accompanied by pain, excessive lacrimation and blepharospasm (spasm of the eyellds). There is frritation and running of the nose with a burning sensation in the nose, mouth and throat and a feeling of intense discomfort during which these subjects cough, often violently. If the exposure continues, the discomfort spreads to the chest and there is difficulty in breathing, and many subjects describe a tightness of the chest or pain as the worst symptom. At this stage most individuals are acutely apprehensive and highly motivated to escape from the smoke. However if exposure continues there is some remission of signs and symptoms.

Among fire victims reports are conflicting. Some people say they went through dense smoke without experiencing any great discomfort, while others say that respixatory difficulties prevented them from entering smoke fllled areas (33). Anyone who has had bonfire smoke in their eyes will know how painful the experience can be. Fowever, the effects can be mitigated by blinking or shutting the eyes, and the effects on the nose can be mitigated by mouth breathing and breath holding. Also, it is known that people are often unaware of painful stimuli when in emergency situations (34). It is therefore likely that irritant smoke products do have some effects on the escape capability of fire victims, but it is not possible at present to determine the degree of incapacitation.

\section{FIRE SCENARIOS AND VICTIM INCAPACITAIION}

From the point of view both of product composition and toxic hazard, it is possible to distinguish three basic types of fire situations:

1. Smouldering fires where the victum may be in the room of origin of the fire or a remote location.

2. Early flaming fires where the victim is in the room of origin.

3. Fully developed or post-flashover fires where the victim is remote from the fire.

In the UK $80 \%$ of fire deaths and injuries occur in domestic dwellings, and in most cases the casualties occur in the compaxtment of origin of the fire. This class of fire is responsible for the highest incidence of deaths $(60 \%)$ and a high incidence of injuries (398), and these fires occur mostly in living rooms or bedrooms, and in upholstery or bedding(2). In these cases fire is often confined to the material first ignited. The toxic hazard in such fires depends upon whether there is a long period of smouldering, or whether there is a rapidly growing flaming fire.

With smouldering fixes the decomposition temperatures axe relatively $10 \mathrm{~W}\left(\sim 400^{\circ} \mathrm{C}\right)$ and materials are decomposed into a mixture of pyrolysis and oxidation fragments containing mixtures of narcotic and irritant gases and particulates. Under these conditions the highest yields of a great variety of products are formed, many of which are ixxitant. Also incomplete oxidation is favoured and $\mathrm{CO}_{2} / \mathrm{CO}$ ratios approach unity, so that $\mathrm{CO}$ is likely to be an important toxic factor. The formation of high yields of ucN is however not normally favoured(11). Although toxic products are formed under these concitions the rate of evolution is slow, smoke is seldom dense and room temperatures are relatively low. A potential. victim therefore has ample time to escape if alerted sufficiently early, but may be overcome by fumes after a long period of time if unaware of the danger, particularly if asleep. Here the main danger is almost certainly naxcosis by $C O$, with possibly a small contribution from low $\mathrm{O}_{2}$ if the victim is in a room with poor air supply $(6,35,36)$. It is not possible from fire statistics to determine how common this type of fire is, since in many cases smouldering fires become flaming fires before they are detected. However, it is likely that fires which are estimated to have burned for 30 minutes or more before discovery have involved long term smouldering, and it may be relevant that deaths are twenty times more likely in this situation, than for fires discovered within 5 minutes of ignition, which are often rapidly growing flaming fires (2).

For flaming fires where the victim is in the room of origin the hazard relates to the early stages of fire growth. Such fires often grow quickly, but even the most rapidly growing flaming fires take approximately 3 minutes to reach levels of heat and gases hazardous to life(37), which should allow ample time to escape from a room, and of course most people do escape. As Figure 2 shows the hazard in this situation relates to a number of factors all of which may reach life threatening levels simultaneously as the fire reaches the rapid phase of exponential growth. In the high temperature, well 
FIGURE 2

SMOKE, HEAT AND GASES DURING SINGLE CHAIR ROOM BURN

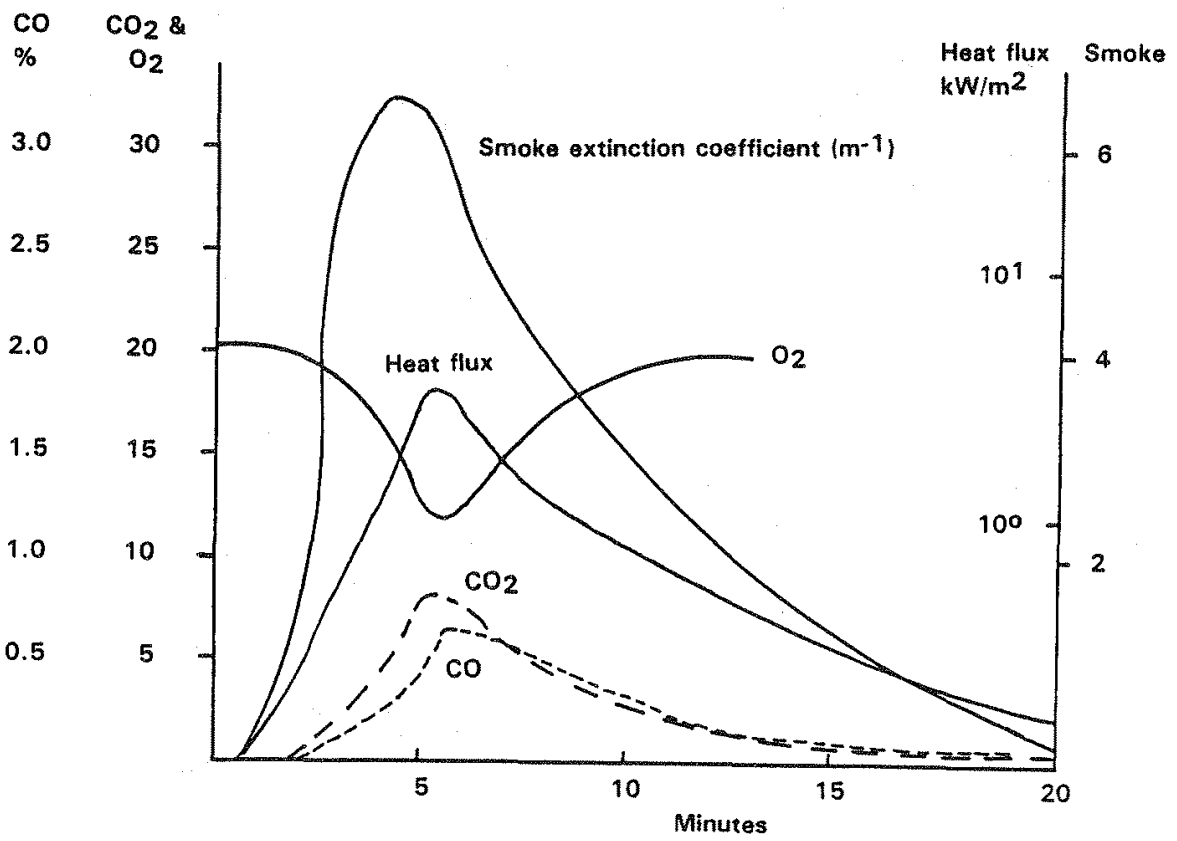

Armchair - Polystyrene with polyurethane cushions and covers.

Room $\quad 29 \mathrm{~m}^{3}$, open doorway. Gases measured in doorway at $2.1 \mathrm{~m}$ height. FROM BABRUSKAS 1979

oxygenated flames of early flaming fires most thermal decomosition products are consumed to form simple comparatively innocuous products such as $\mathrm{CO}_{2}$ and water, the $\mathrm{CO}_{2} / \mathrm{CO}$ ratios being in the 200-1000 range initially. Since $\mathrm{CO}$ is approximately 10-50 times as toxic as $\mathrm{CO}_{2}$ it is thus concievable that in this type of fire $\mathrm{CO}_{2}$ could present more of a narcotic hazard than $\mathrm{CO}$. However as the $\mathrm{CO}_{2}$ concentration in the fire compartment approaches 58 and the $\mathrm{O}_{2}$ concentration decreases towards $15 \%$ the combustion becomes less efficient and the $\mathrm{CO}_{2} / \mathrm{CO}$ ratios decrease to the region of 50-100 and co tends to become a more important factor. Nevertheless as the armchair burn in Figure 2 shows the atmospheres obtained in a rapidly growing fire can contain narcotic concentrations of $\mathrm{CO}_{2}$ $(>58), \mathrm{CO}(>1000 \mathrm{ppm})$ and low oxygen $\left(<15 \% \mathrm{O}_{2}\right)$. In addition some of the pyrolysis products escape the elame zone giving rise to potentially irritant smoke. A victim in this situation is therefore likely to be confronted simultaneously by high temperatures and heat radiation, smoke and high concentrations of $\mathrm{CO}$ and $\mathrm{CO}_{2}$ accompanied by $\mathrm{Low}_{2}$. any one of which could incapacitate a victin and prevent escape.

The inability of victims to escape from such fires seems to depend upon a number of factors. Casualties include a higher proportion of young children and old people than does the general population (for over $65 \mathrm{~s}$ fatalities in bedding fires 7 times that expected from population distribution - 1978) (38), and people who are incapacitated by a previous period of smouldering or by some other infirmity (such as a physical disability, alcohol or drug intoxication) are obviously more at risk(7). However there seem to be two other factors of importance, the behaviour of the victim and the exponential rate of fire development. 
In many cases the victim has a short period in which to carry out the correct actions enabling escape, after which he is rapidly trapped. Some victims may be as leep during this critical escape 'window', but there are also reports of situations where the victim was aware of the fire from ignition, but remained in an attempt to extinguish the fire or for some other reason failed to leave before the phase of very rapid fire growth when heat and narcotic gases rapidly reach life threatening levels. Another, perhaps surprising finding is that victims often appear to be unaware of the fire, and remain to be discovered in a bumed out chair or bed. The insidious nature of $\infty$ intoxication has been described and it also seems that irritant smoke products often fail to wake sleeping victims, although a sudden noise such as of breaking giass may do so. Other victims appear to have roused themselves at some stage, but have been overcome, again probably by $C O$ or BCN before they are able to escape, and are found behind a door. There are also cases reported by survivors where a victim has attempted to extinguish a rapidly growing flaming fire, but failed to leave in time and is discovered near the fire having been overcome by fumes $(35,36)$.

The thira scenario. is where casulaties occur remote from the source of the fire. Apart from being a common occurrence in domestic dwellings, such situations often occur in public bulldings where the situation involves fire which has spread from the material first ignited to others. Materials in such fires are subjected to substantial external flux and in some cases to oxygen deficient environments. Under the severe conditions found in such high temperature post-flashover fires where oxygen concentrations are low, the basic pyrolysis products break down into low molecular weight fragments and can contain high concentrations of narctoic substances such as $\mathrm{CO}$ and $\mathrm{HCN}$, with $\mathrm{CO}_{2} / \mathrm{CO}$ ratios of $<10(11)$.

Under such conditions a building can fill rapidly with a lethal smoke capable of causing incapacitation and death within minutes. Fires where the victim is remote from the compartment of origin are responsible for the highest incidence of non-fatal casualties (48\%) and a large proportion of deaths (37\%)(2). The victim is five times more likely to be killed by smoke than by burns, and is often unaware of the fire during the crucial early phase, so that the gases may not penetrate to the viotim until the fire has reached its rapid growth phase and the victim is already trapped. The major causes of incapacitation and death in this type of fire are almost certainly narcotic gases, particularly Co, which can build up rapidly to high concentrations, although the role of irritants in causing incapacitation and impeding escape attempts may be crucial.

COMMENT

The severe narcotic incapacitation and subsequent deaths of many fire victims is almost certain ly due to the common narcotic gases.

However, the importance of irritants in impeding escape is unknown, and from narcotic gas profiles it is not obvious why so many fatalities occur in the room of fire origin. Useful information may be obtainable from survivors who have experienced exposure to dense, irritant smokes and from case studies of 'room of origin' fires.

\section{POSSIBLE ROUTES TO MITIGATION OF TOXIC BAZARD}

For smouldering fires it would be an advantage. if materials were designed to self extlnguish, and if the formation of products other than $c 0$ during decomposition could be encouraged (such as oxidised hydrocarbon fragments or $\mathrm{CO}_{2}$ ). Early audible waming by smoke alarms may be particularly advantageous as sound often appears to alert victims where the presence of irritant smoke or heat fails.

For early flaming fires where the victim is in the room or origin, any measure which linits the rate of growth once ignition has occurred will give a victim more time to extinguish a small fire or escape from a growing one.

For fully developed fires where the victim is remote from the point of origin the most important mitigating factors are probably early warning and containment of the fire and gases within the original fire compartment. 


\section{REFERENCES}

1. Bowes, P.C., "Smoke and Toxiclty Hazards of Plastics in Fires", Annals of occupational Hygiene, $17: 143-157,1974$.

2. United Kingdom. Fire Statistics 1980. London, Home Office, Published annually.

3. Anderson, R.A., Croce, P.A., Feeley, F.G. and Sakura, J.D., "Study to Assess the Feasibility of Incorporating combustion Toxicity Requirements into Building Material and Furnishing Codes of New York State", A.D. Little, Reference 88712, 1983.

4. Sarkos, C.P., Hi11, R.G. and Howe11, W.D., "The Development and Application of a Ful1-scale wide Body Test Article to study the Behavioux of Interior Materials During a Postcrash Fuel Fire", AGARD-LS-123, 601-621, 1982.

5. Purser, D.A., "Combustion Toxicology Research and Animal Models", Society of the plastics Industry meeting. H1lton Bead S.C. U.S.A., August 9th, 1983.

6. Purser, D.A. and Woolley, W.D., "Biological Studies of Combustion Atmospheres", Journal of Fire Sciences, 1: 118-144, 1983.

7. Anderson, R.A., Watson, A.A. and Harland, W.A., "Fire Deaths in the Glasgow Area: 1. General. Conclusions and Pathology", Medicine, Science and Law, 21: 175-183, 1981.

8. Purser, D.A., "A Bloassay Model for Testing the Incapacitating Effects of Exposure to Combus tion Product Atmospheres using Cxnomolgus Monkeys", Journal of fire Sciences, $2: 20-36,1984$.

9. Purser, D.A. and Berri11, K.R., "Effects of Carbon Monoxide on Behavioux in Monkeys in Relation to Human Fire Hazard", Archives of Environmental Health 38 : 308-315, 1983.

10. Luft, U.C., "Aviation Physiology - The Effects of Altitude", in "Handbook of Physiology. Section 3: Respiration", eds. W.O. Fenn and H. Rahn, 11lo, American Physiological society, Washington D.C., 1965.

11. Woolley, W.D. and Fardell, P.J., "Basic Aspects of Combustion Toxicology", Fire Safety Journal, $5: 29-48,1982$.

12. Stewart, R.D., Peterson, J.E., Baretta, E.D., Dodd, H.C. and Herrmann, A.A., "Experimental Human Exposure to Carbon Monoxide". Archives of Envixonmental gealth $21: 154-164,1970$.

13. "Carbon Monoxide Poisoning Due to Faulty Gas Water Heaters in British Holidaymakers on the Algarve". "Sunday Times", 1983.

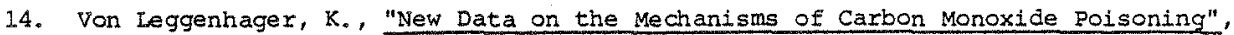
Acta Medica Scandanavica, 196/suppl: 563, 1-47, 1974.

15. Peterson, J.E. and Stewart, R.D., "Predicting the Carboxyhaemoglobin Levels Resulting From Carbon Monoxide Exposure", Journal of Applied physiology, 39 : $633-638,1975$.

16. Anderson, R.A., Thompson, Io and tarland, W.A., "The importance of Cyanide and organic Nitriles in Fire Fatalities", Fire and Materials, 3:91-99, 1979.

17. Clark, C.J., Campbell, D. and Reid, W.H., "Blood Carboxyhaemoglobin and Cyanide Levels in Fire Survivors", Lancet, June 20th: 1332-1335, 1981.

18. Purser, D.A., Grimshaw, P. and Berrill, K.R., "The Role of Hydrogen Cyanide in the Acute Toxicity of the pyrolysis products of polycarylonitrile", Archives of Environmental Health, $39: 394-400,1984$.

19. Ballantyne, B., "Artifacts in the Defintion of Toxicity by Cyanides and Cyanogens", Fundamental and Applied Toxicology, $3: 400-408,1983$.

20. Kimmerle, G. " "Aspects and Methodology for the Evaluation of Toxicological Parameters During Fire Exposure", Journal of Combustion Toxicology, 1 : 4-50, 1974.

21. Haldane, J.S., "Respiration", New Haven : Yale University Press, 1922. 
22. Schulte, J.E., "Sealed Environments in Health and Disease", Archives of Environmental Health, 8: 427-452, 1964 .

23. Documentation of the Threshold wimit Values for Substances in workroom Air. American Council of Govemmental Industrial Hygienists, 1980.

24. Purser, D.A., "The Role of Narcosis by Common Fire Toxicants", in Toxic lazards From Fire, ed. GE Hartzel1, Technomic, Lancaster P.A., 1984.

25. Purser, D.A. and Buckley, P., "Lung Irritance and Inflammation During and After Exposure to Themal Decomposition Products From Polymeric Materials", Medicine, Sclence and Law, 23 : 142-150, 1983.

26. Campbel1, D., "Respiratory Tract. Trauma in Burned Patients", Research Colloquim "People and Fire", Fire Research Station, Borehamwood, 1985.

27. Kane, L., Barrow, C.S. and Alarie, Y., "A Short-term Test to Predict Acceptable Levels of Exposure to Airborne Sensory Irritants", American Industrial Hygiene Association Journal $40: 207-229,1979$.

28. Punte, C.L., Owens, E.J. and Gutentag, P.J.. "Exposure to Ortho-chlorobenzylidene Malonitrile", Archives of Environmental Health, $6: 366-374,1963$.

29. Beswick, F.W., Holland, P. and Kemp, K. H., "Acute Effects of Exposure to Orthochlorbenzylidene malonitrile (CS) and the development of tolerence", British Journal of Industrial Medicine, $29: 298-306,1972$.

30. Jin, T., "Studies of Emotional Instability in Smoke from Fires", Journal of Fire and Flammability, 12 : 130-142, 1981.

31. Alarie, Y., "Sensory Irrittation by Airborne Chemicals", CRC Critical Reviews of Toxicology, $2: 299-363,1973$.

32. Kaplan, H.L., Grand, A.F., Rogers, W.R., Switzer, W.G. and Hartzel1, G.C., "A Research Study of the Assessment of Escape Impairment by Irritant Combustion Gases in Postcrash Aircraft Fires", Report No. DOT/FAA/CT-84/16, 1984.

33. Canter, D., "Studies of Human Behaviour. in Fire: Empirical Results and their Implications for Education and Design", University of Surrey, June, 1983.

34. Melzack, R. and Wal1, P.D.., "Pain Mechanisms : A New Theory", Science, 150 : $971-979,1965$.

35. Sileock, A., Robinson, D. and Savage, N.P., "Fires in Dwellings - An investigation of Actual Fires. Part II; Hazards from Ground-floor Fires, Part III; Physiological effects of fire", Building Research Establishment Current Paper CP80/78, 1978.

36. Purser, D.A., Unpublished data obtained from case reports, fire investigations and personal comminications involving the Fire Research Station, Home Office and UK Fire Brigades, 1982-1985.

37. Babrauskas, V., "Ful1-scale Burning Behaviour of Upholstered Chairs", National Bureau of Standards Technical Note. 1103, 1979.

38. "A Statistical Review of Fire starting in Textiles or Funiture in Dwellings in the United Kingdom", Home Office 53 Division, October, 1980. 